\title{
PARÂMETROS DE DESEMPENHO DE DEZESSEIS EQUIPAMENTOS DE IRRIGAÇÃO POR PIVÔ CENTRAL
}

\author{
Parameters of performance of sixteen center-pivot irrigation equipments
}

\author{
Delvio Sandri' ${ }^{1}$, Diego de Andrade Cortez ${ }^{2}$
}

\begin{abstract}
RESUMO
O tempo de uso de sistemas de irrigação por pivô central pode resultar em alteração de suas características hidráulicas, necessitando de avaliações periódicas para manter a uniformidade de distribuição de água em níveis aceitáveis. Objetivou-se, neste trabalho, avaliar as condições de funcionamento e desempenho de dezesseis pivôs centrais, localizados em onze municípios de Goiás e no Distrito Federal. Estimou-se o coeficiente de uniformidade de Heermann \& Hein - CUH e uniformidade de distribuição - CUD, variação da lâmina coletada em relação à projetada e os fatores que interferem no desempenho dos equipamentos. Dos pivôs avaliados, quatro $(25 \%)$ apresentaram CUH inadequado $(<80 \%)$ e três $(18,75 \%)$ apresentaram CUD inadequado $(<70 \%)$. A lâmina média coletada foi superior à projetada em três e inferior em treze pivôs, com diferença maior que $10 \%$ em apenas um pivô. A maioria dos pivôs avaliados necessita de manutenção para solucionar algum dos seguintes problemas: bocais com vazão diferente da considerada adequada para alguns intervalos dos equipamentos, emissores total ou parcialmente obstruídos ou danificados, ausência de pendurais, reguladores de pressão danificados, vazamentos em vários pontos da lateral e velocidade de deslocamento em campo diferente da indicada no relé porcentual.
\end{abstract}

Termos para indexação: Lâmina de irrigação, uniformidade, eficiência de irrigação.

\section{ABSTRACT}

The time of use of the center-pivot irrigation system may result in alteration of the hydraulic characteristics, frequent evaluations being needed to maintain the efficiency of water distribution at acceptable levels. The aim of this work was to evaluate the conditions of the use and the performance of sixteen center pivots, located in eleven municipal districts of Goiás State and Federal District, Brazil. The Heermann \& Hein - CUH coefficient of uniformity and coefficient of distribution - CUD, variation between the collected and projected depth and verification of the main factors that influenced the performance were evaluated. Among the evaluated pivots, four (25\%) presented inadequate CUH $(<80 \%)$ and three $(18.75 \%)$ presented inadequate CUD $(<70 \%)$. The average depth applied was higher than the projected in three and lower in thirteen pivots, with the difference higher than $10 \%$ in only one pivot. Most of the evaluated pivots need maintenance to solve the following problems: emitters with flow rate different from the flow considered appropriate for some intervals of the equipments; emitters totally or partially clogged or damaged; absence of suspension strings; damaged pressure regulators; leaks in several points and speed displacement different from the observed on the relay percentile.

Index terms: Water depth, uniformity, irrigation efficiency.

(Recebido em 8 de junho de 2007 e aprovado em 3 de setembro de 2008)

\section{INTRODUÇÃO}

O sistema de irrigação por pivô central expandiu-se acentuadamente no Brasil nos últimos anos, mais notadamente nos estados de São Paulo, Goiás, Minas Gerais e Bahia, motivado pelas facilidades operacionais e de controle da lâmina de irrigação, com custos competitivos pelo menor dispêndio de mão-de-obra e pela possibilidade de obter-se alta eficiência de aplicação e distribuição de água.

O Brasil possui uma área irrigada total de 3.440 .470 ha, sendo que desses, 710.553 ha são com pivô central (CHRISTOFIDIS, 2006). O estado de Goiás possui uma área de $340.166 \mathrm{~km}^{2}$, onde cerca de 1,2 milhões de ha têm potencial para irrigação. A agricultura irrigada é uma atividade de grande importância para sua economia, vivenciando uma acentuada expansão nas últimas décadas, popularizando-se pela utilização da irrigação por pivô central, principalmente em culturas extensivas, como o feijão, tomate, trigo, milho, pastagem, soja, girassol, café e batata, gerando emprego e renda. Estima-se que existam instalados cerca de 2.000 pivôs, que cobrem cerca de $75 \%$ da área total irrigada, que é de 198.100,00 ha. A irrigação em Goiás contribui com cerca de $10 \%$ da produção estadual e utiliza 3,5\% da área total cultivada (GOIÁS, 2004). Cristalina é o município com maior área irrigada do estado de Goiás,

'Engenheiro Agrícola, Doutor - Universidade Estadual de Goiás/UEG - BR 153, no 3.105, Campus Henrique Santillo, Fazenda Barreiro do Meio - Cx. P. 459 - 75132-400 - Anápolis, GO - sandri@ueg.br

${ }^{2}$ Engenheiro Agrícola - Agrosul Máquinas Agrícolas - Avenida Dioclecio Severino Ramos, Trevo - 47850-000 - Luiz Eduardo Magalhães, BA cortez@yahoo.com.br 
onde também se concentra o maior número de pivôs, com cerca de 400 equipamentos.

Como qualquer outro sistema de irrigação, o objetivo do pivô central é distribuir água de maneira uniforme e controlada na área irrigada, sendo considerado um dos fatores mais importantes na sua operação, interferindo no consumo de energia, nos efeitos desfavoráveis sobre a produtividade por unidade de água aplicada e no meio ambiente (BERNARDO et al., 2006; HEINEMANN et al., 1998).

Os fatores que afetam a uniformidade de distribuição da água são os climáticos, como a evaporação, temperatura do ar, umidade relativa e condições locais do vento e os fatores não climáticos, que são os relacionados ao equipamento de irrigação, como a pressão de operação do emissor, velocidade e alinhamento da linha lateral e altura do emissor (HEINEMANN et al., 1998). O coeficiente de uniformidade de distribuição de água é uma medida freqüentemente utilizada como indicador dos problemas de distribuição da irrigação (FRIZZONE, 1992). Heinemann $\&$ Frizzone (1995) observaram que o aumento do coeficiente de uniformidade de Christiansen (CUC) em um pivô central, de $81,2 \%$ para $94,0 \%$, em relação aos graus de adequação de $75 \%, 80 \%$ e $85 \%$, resultou em uma economia no volume de água aplicada de $11,86 \%, 14,24 \%$ e $16,68 \%$, respectivamente.

Com a maior importância dada ao conceito de uniformidade de distribuição da água em sistemas de irrigação nos últimos anos, em decorrência da crescente necessidade de conservação dos recursos hídricos e competitividade pelos mesmos, alto custo da energia e de outros insumos e à falta de garantias aos preços dos produtos agrícolas, a escolha e uso adequado dos sistemas de irrigação, além da adoção de métodos apropriados de manejo da água, devem ser sempre considerados. Sano et al. (2005) estudaram a variação na demanda de água para irrigação por pivô central no Distrito Federal entre 1992 e 2002, observando que o número de pivôs passou de 55 para 104, a área irrigada de 3.894 ha para 6.823 ha e o consumo de água de 23,36 para 40,94 milhões de $\mathrm{m}^{3}$ ano $^{-1}$, indicando tendência de superar o consumo humano.

Os produtores agrícolas, na maioria das vezes, reconhecem a necessidade de controlar a quantidade de sementes, adubação, defensivos agrícolas, dentre outros insumos. No entanto, a necessidade de medir ou controlar o volume de água aplicada na irrigação é quase sempre ignorado, devido à visão de não se caracterizar como uma medida para reduzir os custos de produção, ou porque a cobrança pelo uso dos recursos hídricos ainda não está implantada na maior parte do pais ou mesmo por tradição.
Objetivou-se, neste trabalho, avaliar alguns parâmetros de desempenho e as condições de funcionamento de 16 pivôs centrais, a partir da análise do coeficiente de uniformidade de Heermann \& Hein (1968) CUH, coeficiente de uniformidade de distribuição - CUD, variação da lâmina medida em relação à projetada e dos fatores que estão interferindo no desempenho dos equipamentos.

\section{MATERIAL E MÉTODOS}

Avaliaram-se 16 sistemas de irrigação por pivô central (PC), no período de 06/09/2003 a 13/09/2005, 12 localizados no Estado de Goiás e 4 no Distrito Federal (Tabela 1).

Os ensaios para determinação da lâmina de irrigação e a uniformidade de distribuição de água seguiram a norma ABNT-NBR: 14244 (ABNT, 1998). Os coletores foram instalados em duas fileiras radiais a partir do ponto central do pivô, formando um ângulo de $3^{\circ}$, espaçados de $3 \mathrm{~m}$ entre si. Utilizaram-se canecas coletoras de água, com diâmetro da "boca" de 0,08 m e altura de 0,102 m, fixadas em hastes cilíndricas de alumínio de $0,75 \mathrm{~m}$ de altura.

A pressão do conjunto motobomba foi ajustada de acordo com as recomendações técnicas do projeto de cada equipamento após seu acionamento, permitindo uma variação de, no máximo, 5\% durante o ensaio. Na linha lateral de cada pivô, as pressões foram medidas no ponto inicial, intermediário e final, com um manômetro de Bourdon com glicerina, com escala de 0 a $1000 \mathrm{kPa}$, com conexão para tubo Pitot.

A lâmina de água precipitada em cada coletor foi medida utilizando uma proveta confeccionada em termoplástico transparente, diâmetro de $0,037 \mathrm{~m}$ e altura de $0,11 \mathrm{~m}$ e precisão de $1 \mathrm{~mm}$, tão logo o pivô deixava de aplicar água sobre o coletor. Sempre que os volumes coletados além do comprimento efetivo do equipamento fossem menores que $70 \%$ do volume médio coletado, eram eliminados da análise dos coeficientes de uniformidade. A lâmina coletada foi comparada à projetada, obtida dos dados técnicos do projeto de cada equipamento.

A velocidade da última torre foi analisada medindose o tempo com que o último rodado levava para percorrer uma distância de $50 \mathrm{~m}$, com o auxílio de um cronômetro digital, com precisão $0,01 \mathrm{~s}$, repetindo-se três vezes em cada ensaio. A velocidade do vento foi medida com um anemômetro manual, com uma margem de erro de $10 \%$, posicionado a uma altura de 2,0 $\mathrm{m}$ do solo, evitando-se realizar o ensaio com ventos acima de $3,0 \mathrm{~m} \mathrm{~s}^{-1}$. Para controle da água evaporada durante o ensaio, foram colocados fora da área de irrigação quatro coletores com volume de $50 \mathrm{~mL}$ de água, estimada pela diferença da medida registrada no final e início do ensaio. 
Tabela 1 - Descrição do fabricante, fazenda, município, hora do ensaio (He), área irrigada (Ai), raio da última torre (Ru), distância entre torres (Dt) e ajuste do relê porcentual (Ar).

\begin{tabular}{llllccccc}
\hline Pivôs & \multicolumn{1}{c}{ Fabricante } & \multicolumn{1}{c}{ Fazenda } & Município & He & $\begin{array}{c}\text { Ai } \\
(\text { ha })\end{array}$ & $\begin{array}{c}\text { Ru } \\
(\mathrm{m})\end{array}$ & $\begin{array}{c}\text { Dt } \\
(\mathrm{m})\end{array}$ & $\begin{array}{c}\text { Ar } \\
(\%)\end{array}$ \\
\hline PC 01 & Krebsfer & Recanto & Pontalina & $16: 50$ & 73,17 & 456,90 & 48,50 & 100 \\
PC 02 & Cielt & Escola Araçú & Araçú & $08: 00$ & 35,40 & 311,70 & 46,20 & 100 \\
PC 03 & Carborundum & Bom Jardim & Piracanjuba & $16: 30$ & 53,24 & 381,85 & 47,88 & 100 \\
PC 04 & Valley & Bom Sucesso & Joviânia & $09: 00$ & 63,60 & 418,46 & 48,20 & 100 \\
PC 05 & Krebsfer & Cigana & Goianésia & $07: 00$ & 57,93 & 409,60 & 45,70 & 100 \\
PC 06 & Carborundum & Caução de Couro & Goianésia & $07: 30$ & 40,70 & 331,80 & 47,88 & 80 \\
PC 07 & Carborundum & Cristalina & Vila Propício & $16: 30$ & 103,35 & 545,67 & 47,88 & 82 \\
PC 08 & Valley & São Nicolau & Cristalina & $07: 20$ & 72,59 & 455,40 & 48,20 & 80 \\
PC 09 & Irrigabrás & Bela vista & Indiara & $05: 00$ & 96,07 & 535,00 & 53,50 & 80 \\
PC 10 & MTU & Fantástico & Campestre & $16: 20$ & 27,60 & 278,40 & 48,20 & 80 \\
PC 11 & Valley & Agropecuária OK & Paranoán & $12: 00$ & 92,76 & 522,80 & 48,20 & 60 \\
PC 12 & Carborundum & Inhumas & Matrinchã & $16: 20$ & 121,38 & 594,57 & 47,88 & 66 \\
PC 13 & Valmatic & Itapeti/Mariana & PAD, DF & $16: 20$ & 26,30 & 271,26 & 45,21 & 65 \\
PC 14 & Dantas & Itapeti/Mariana & PAD, DF & $16: 20$ & 112,13 & 582,92 & 44,84 & 88 \\
PC 15 & Dantas & Itapeti/Mariana & PAD, DF & $16: 20$ & 109,36 & 570,68 & 44,84 & 62 \\
PC 16 & Dantas & Itapeti/Mariana & PAD, DF & $16: 20$ & 111,10 & 570,68 & 44,84 & 40 \\
\hline
\end{tabular}

O coeficiente de uniformidade de Christiansen (1942) - CUC, foi o primeiro índice proposto, sendo o mais utilizado para quantificação da uniformidade de distribuição de água em irrigação, por aspersão convencional (REZENDE et al., 2002). No entanto, Heermann \& Hein (1968) propuseram modificação dessa equação para aplicação em sistemas pivô central, gerando o coeficiente de uniformidade de Heermann \& Hein (1968) - CUH (Equação 1).

$$
\mathrm{CUH}=100\left[1-\left(\frac{\sum_{\mathrm{i}=1}^{\mathrm{n}}\left|\mathrm{X}_{\mathrm{i}}-\mathrm{X}_{\mathrm{MP}}\right| \mathrm{S}_{\mathrm{i}}}{\sum_{\mathrm{i}=1}^{\mathrm{n}} \mathrm{X}_{\mathrm{i}} \mathrm{S}_{\mathrm{i}}}\right)\right]
$$

em que,

CUH - coeficiente de uniformidade de Heermann \& Hein $(\%)$;

n - número de coletores utilizados na análise de dados;

i - número designado para identificação de um coletor em particular;

$\mathrm{X}_{\mathrm{i}}-$ precipitação coletada no i-ésimo coletor $(\mathrm{mm})$; $\mathrm{S}_{\mathrm{i}}$ - distância do i-ésimo coletor ao ponto pivô;

$\mathrm{X}_{\mathrm{MP}}$ - precipitação média ponderada coletada $(\mathrm{mm})$, dada pela Equação 2.

$$
X_{M P}=\frac{\sum_{i=1}^{n} X_{i} S_{i}}{\sum_{i=1}^{n} S_{i}}
$$

O coeficiente de uniformidade de distribuição (CUD) foi estimado pela Equação 3.

$$
\mathrm{CUD}=100\left(\frac{\sum_{\mathrm{i}=\mathrm{p}}^{\mathrm{q}} \mathrm{NiXi}}{\mathrm{X}_{\mathrm{MP}} \sum_{\mathrm{i}=\mathrm{p}}^{\mathrm{q}} \mathrm{Ni}}\right)
$$

em que,

CUD - coeficiente de uniformidade de distribuição (\%);

$\mathrm{Ni}=\mathrm{i}-0,5$;

p - número de ordem do primeiro elemento da série crescente de lâminas coletadas;

q - número de ordem do elemento da série crescente de lâminas coletadas que faz com que $\sum_{\mathrm{i}=\mathrm{p}}^{\mathrm{q}} \mathrm{Ni}$ atinja aproximadamente $25 \%$ da sua soma total. 
A classificação do CUH e CUD foi feita pela ABNT:NBR 14244 (ABNT, 1998), (Tabela 2).

Tabela 2 - Classificação do CUH e do CUD.

\begin{tabular}{ccc}
\hline CUH (\%) & CUD (\%) & Classificação \\
\hline$<80$ & $<70$ & Ruim \\
80 a 84 & 70 a 74 & Regular \\
85 a 89 & 75 a 81 & Boa \\
$>90$ & $>82$ & Muito Boa \\
\hline
\end{tabular}

\section{RESULTADOS E DISCUSSÃO}

Os valores de velocidade da última torre, velocidade do vento, evaporação durante o ensaio, lâmina projetada, lâmina média coletada, variação da lâmina projetada em relação à coletada, CUH, CUD e classificação de acordo com ABNT-NBR: 14244 (ABNT, 1998) são apresentados na Tabela 3.

Dos pivôs avaliados, em 18,75\% a classificação do CUH e do CUD foi considerada "muito boa"; em 31,25\% apresentaram CUH "boa" e em 37,5\% o CUD como "boa"; em $25 \%$ o CUH e CUD foram "regular" e em $25 \%$ o CUH foi "ruim" e em 18,75\% o CUD foi considerado "ruim". Considerando culturas com alto valor comercial, apenas 3 pivôs apresentaram CUH aceitável (> 90\%). Para cultivos extensivos e sistema radicular médio, 5 pivôs apresentaram índices adequados (85\% a 90\%). Em cultivos com sistema radicular profundo, 4 pivôs apresentaram índices adequados (80\% a 85\%), sendo que 4 pivôs não atendem a nenhum desses critérios $(<80 \%)$ (BERNARDO et al., 2006). Três desses 4 pivôs apresentaram CUD $<70 \%$, não satisfazendo aos índices mínimos aceitáveis pela literatura, sendo um número elevado, considerando-se que os investimentos para implantação do pivô são elevados e, normalmente, cultivam-se culturas de alto valor comercial. Demonstram ainda, o descaso com a manutenção dos equipamentos por parte do agricultor, que tem demonstrado maior preocupação com investimentos em insumos para implantação das culturas e também devido à falta de orientação técnica, tanto por parte das empresas que comercializam esses equipamentos, bem como dos órgãos de assistência técnica municipal e estadual. As conseqüências imediatas da falta de manutenção dos equipamentos e manejo inadequado da irrigação são o maior consumo de energia e impactos ambientais, como erosão, lixiviação de nutrientes e defensivos agrícolas,

Tabela 3 - Velocidade da última torre (Vu), velocidade do vento (Vv), evaporação (Ev), lâmina projetada (Lp), lâmina média coletada $(\mathrm{Lc})$, variação da lâmina coletada em relação à projetada, CUH, CUD e classificação (Clas) de acordo com ABNT-NBR: 14244 (ABNT, 1998).

\begin{tabular}{ccccccccccc}
\hline Pivôs & $\begin{array}{c}\text { Vu } \\
\left(\mathrm{m} \mathrm{h}^{-1}\right)\end{array}$ & $\begin{array}{c}\mathrm{Vv} \\
\left(\mathrm{m} \mathrm{s}^{-1}\right)\end{array}$ & $\begin{array}{c}\text { Ev } \\
(\mathrm{mm})\end{array}$ & $\begin{array}{c}\mathrm{Lp} \\
(\mathrm{mm})\end{array}$ & $\begin{array}{c}\text { Lc } \\
(\mathrm{mm})\end{array}$ & $\begin{array}{c}\text { Variação } \\
(\%)\end{array}$ & $\begin{array}{c}\text { CUH } \\
(\%)\end{array}$ & Clas & $\begin{array}{c}\text { CUD } \\
(\%)\end{array}$ & Clas \\
\hline PC 01 & 266,6 & - & 0,1 & 4,10 & 4,02 & $-1,95$ & 86,25 & boa & 76,32 & boa \\
PC 02 & 205,0 & - & - & 3,86 & 3,95 & $+2,33$ & 87,81 & boa & 81,52 & boa \\
PC 03 & 231,1 & 1,6 & - & 4,40 & 4,34 & $-1,36$ & 85,56 & boa & 78,34 & boa \\
PC 04 & 224,5 & - & 1,0 & 5,85 & 5,60 & $-4,27$ & 93,16 & muito boa & 87,68 & muito boa \\
PC 05 & 174,2 & - & - & 5,28 & 5,13 & $-2,84$ & 82,65 & regular & 73,68 & regular \\
PC 06 & 165,5 & 1,0 & - & 4,96 & 5,03 & $+1,41$ & 88,92 & boa & 80,91 & boa \\
PC 07 & 278,0 & - & - & 4,87 & 4,51 & $-7,39$ & 85,59 & boa & 74,72 & boa \\
PC 08 & 271,4 & 1,8 & - & 5,27 & 5,19 & $-1,52$ & 93,01 & muito boa & 82,50 & muito boa \\
PC 09 & 272,7 & - & - & 5,18 & 4,90 & $-5,41$ & 83,17 & regular & 71,43 & regular \\
PC 10 & 183,4 & 2 & 0,4 & 4,88 & 4,49 & $-7,99$ & 91,44 & muito boa & 86,19 & muito boa \\
PC 11 & 124,9 & 2 & - & 15,31 & 13,27 & $-13,32$ & 60,54 & ruim & 52,55 & ruim \\
PC 12 & 275,5 & 1,5 & - & 6,26 & 6,47 & $-1,37$ & 80,11 & regular & 74,19 & regular \\
PC 13 & 126,6 & 1,2 & - & 10,35 & 10,02 & $-3,19$ & 80,89 & regular & 77,35 & boa \\
PC 14 & 182,3 & 1,5 & - & 7,51 & 6,99 & $-6,92$ & 78,35 & ruim & 67,53 & ruim \\
PC 15 & 184,3 & 1,3 & - & 8,22 & 8,55 & $+4,01$ & 79,37 & ruim & 71,46 & regular \\
PC 16 & 172,4 & 1,5 & - & 16,12 & 5,76 & $-2,37$ & 71,59 & ruim & 64,28 & ruim \\
\hline
\end{tabular}


contaminando as fontes de água superficiais e subterrâneas.

Uma análise mais detalhada ao longo da linha lateral de cada pivô permite detectar com maior precisão os principais fatores que estão interferindo no seu desempenho e propor medidas, que em muitas situações, podem solucionar ou amenizar os problemas observados com procedimentos simples e de baixo custo, implementadas pelo próprio agricultor, dispensando mãode-obra mais qualificada.

De maneira geral, os principais inconvenientes observados e descritos na seqüência, são decorrentes da falta de manutenção periódica do equipamento ao longo do tempo de uso e mau dimensionamento do sistema de bombeamento e dos distribuidores de água ao longo da linha lateral e sistema de automação, como problemas técnicos no relé porcentual. Nos PC 12 e PC 14, as velocidades de deslocamento medidas em campo foram de $66 \%$ e $88 \%$, respectivamente, enquanto que, no relê porcentual, registrou-se $80 \%$ para ambos os equipamentos. Nos PC 13, PC 15 e PC 16 foram observados no painel 90\%, $70 \%$ e $40 \%$ e no ensaio de campo $65 \%, 62 \%$ e $39 \%$, respectivamente, o que concorre para as diferenças em lâmina aplicada projetada e real.

Dos equipamentos avaliados, o PC 11 apresentou o pior desempenho, constatando-se que, a partir do $8^{\circ}$ vão, a lâmina coletada apresentou tendência de redução progressiva, como resultado da queda de pressão do sistema, onde registrou-se $40 \mathrm{kPa}$ na extremidade do pivô, inferior à recomendada em projeto $(180 \mathrm{kPa})$. Com exceção ao $8^{\circ}$ vão (CUH “regular"), todos os demais apresentam CUH "ruim" (<80\%). Pinto et al. (2006) observaram, para o pivô avaliado, que a pressão no final da lateral foi menor que a recomendada e a lâmina de água aplicada ficou abaixo da média e as eficiências de irrigação foram menores do que o recomendado pela literatura como aceitáveis. Rodrigues et al. (2001) observaram na avaliação de um pivô central, que o CUC $(77,97 \%)$ e CUD $(67,12 \%)$ foram inferiores ao aceitável para esse tipo de equipamento, como observado em 4 equipamentos nesse trabalho e que a lâmina média coletada foi inferior à lâmina média projetada, o mesmo ocorrendo em 13 pivôs avaliados. Oliveira et al. (2003) constataram que os índices de CUC e CUD foram muito próximos aos índices mínimos aceitáveis para dois tipos de manejo do solo: preparo com grade aradora $(\mathrm{CUC}=80,66 \%$ e $\mathrm{CUD}=70,83 \%) \mathrm{e}$ plantio direto $(\mathrm{CUC}=81,09 \%$ e CUD $=70,20 \%)$. Bonomo et al. (2003) também observaram índices de CUC e CUD acima dos mínimos aceitáveis. A diferença de uniformidade obtida entre os diferentes equipamentos avaliados, pode ser atribuída, dentre outros fatores, ao tempo de uso dos mesmos, aliada à freqüência de manutenção preventiva e corretiva.

No PC 03, embora seja um equipamento relativamente antigo, a uniformidade obtida foi considerada aceitável, mesmo apresentando uma distância entre emissores maior que os pivôs instalados mais recentemente. No PC 04, com menos de 2 anos de uso, a uniformidade foi aceitável, embora os reguladores de pressão tenham sido instalados para operarem a $69 \mathrm{kPa}$, sugerindo-se por questões hidráulicas, substituir por outros de $103 \mathrm{kPa}$, de forma que os jatos dos aspersores tenham um maior raio de alcance, minimizando o efeito de vento e por conseqüência o surgimento de locais com lâmina insuficiente ou "faixas" com deficiência hídrica. A atuação adequada dos reguladores de pressão tem grande importância sobre a uniformidade de aplicação de água, conforme comprovado por Teixeira et al. (2003), que obtiveram índices de CUC de 94,1\%, 94,0\%, 94,1\% e CUD de $88,9 \%, 89,3 \%, 89,0 \%$, respectivamente, para as condições em declive, nível e aclive, constatando que os reguladores de pressão foram eficientes no equilíbrio da pressão. O mesmo foi observado por Zocoler et al. (2004).

Na Figura 1, apresenta-se a lâmina coletada e lâmina média coletada ao longo da linha lateral de dois pivôs, sendo o que apresentou o maior índice de CUH (93,16\%, PC 04 - Joviânia), Figura 1a e o pivô com o menor índice de CUH (60,56\%, PC 11- Paranoá), Figura 1b.

Os PC 02, PC 06 e PC 15 apresentaram lâmina coletada média maior que a lâmina projetada, sendo os principais fatores a utilização de bocais com diâmetro maior que os considerados adequados e o relê porcentual não estar funcionando adequadamente (Tabela 3 ). Nos locais onde a lâmina aplicada diferir em $10 \%$, para mais ou para menos em relação à lâmina média projetada, conforme ABNT-NBR: 14244 (ABNT, 1998) devem ser investigadas as causas e providenciar as mudanças necessárias. Apenas o PC 11 apresentou diferença maior que $10 \%$ entre lâmina coletada e projetada $(13,32 \%)$, não sendo recomendável, pois, induzirá na aplicação de uma lâmina de água acima ou abaixo da considerada adequada para satisfazer as necessidades hídricas da cultura. 

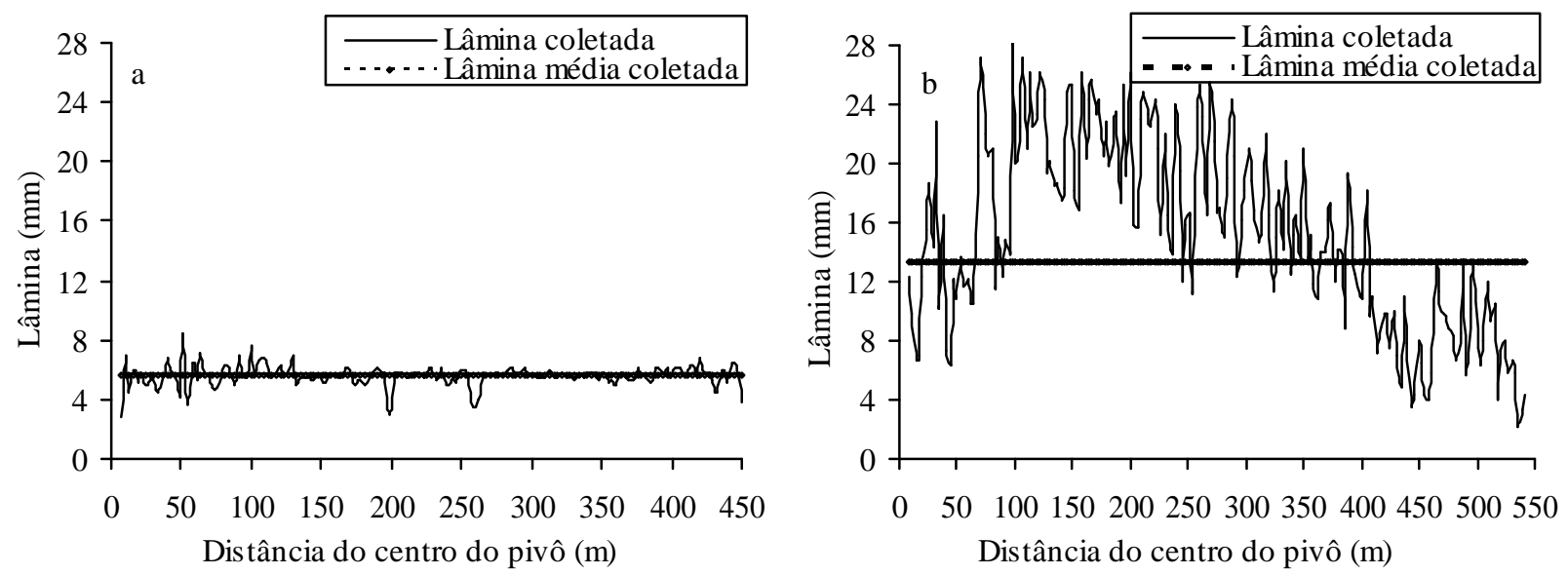

Figura 1 - Lâmina coletada e lâmina média coletada ao longo da linha lateral do PC 04 (a) e PC 11 (b).

A pressão na extremidade do $\mathrm{PC} 08$ foi de $280 \mathrm{kPa}$, quando deveria ser de $130 \mathrm{kPa}$, devido ao conjunto motobomba fornecer uma pressão em sua saída de 1100 $\mathrm{kPa}$, quando deveria ser de $950 \mathrm{kPa}$. A pressão mais elevada resultou no rompimento de várias mangueiras dos pendurais, interferindo na manutenção das condições hidráulicas. No PC 09, a pressão na extremidade que deveria ser de, no máximo, $180 \mathrm{kPa}$, foi de $380 \mathrm{kPa}$, garantindo uma ótima pressurização do sistema, no entanto, ficou sujeita à ação do vento devido a maior fragmentação do jato de água. A solução mais viável, tecnicamente, é substituir os bocais dos aspersores por outros de maior vazão, ajustando-os à pressão do sistema. No PC 10, a pressão no final do pivô foi de $160 \mathrm{kPa}$, quando deveria ser de 180 $\mathrm{kPa}$, devido à potência da motobomba ser inferior à necessária, comprometida pelo desnível de $4 \mathrm{~m}$ entre o ponto fixo e a extremidade do pivô. No PC 13, a pressão de projeto no centro era $307 \mathrm{kPa}$ e no final de $200 \mathrm{kPa}$, no entanto, foram observadas pressões de $260 \mathrm{kPa}$ e $157 \mathrm{kPa}$, respectivamente, mesmo assim a lâmina coletada $(10,35$ $\mathrm{mm}$ ) foi semelhante à projetada $(10,02 \mathrm{~mm})$. No PC 14 , a pressão no centro do pivô foi de $700 \mathrm{kPa}$ e na extremidade final de $100 \mathrm{kPa}$, quando deveriam ser de 807 e $200 \mathrm{kPa}$, respectivamente, resultando em uma lâmina muita baixa nos últimos 3 vãos. Nos demais pivôs, as pressões foram consideradas adequadas segundo dados técnicos de projeto e observações realizadas.

No PC 01, a lâmina coletada foi inferior à projetada no $1^{\circ}$ vão, entre o $3^{\circ}$ e $4^{\circ}$ vão, no final do $4^{\circ}$ vão, no início do $6^{\circ}$, no final do $7^{\circ}$ vão e no início do lance em balanço, decorrente de alguns emissores parcialmente obstruídos. Nesse pivô, o "kit" de aspersores apresentava cerca de 4 anos de uso, sugerindo-se assim a limpeza ou substituição dos emissores total ou parcialmente obstruídos ou danificados. Com exceção ao $2^{\circ}$ vão do PC 11 e no $1^{\circ}, 2^{\circ}, 8^{\circ}$, $11^{\circ}$ vãos do PC 12 e no lance em balanço, a lâmina coletada foi maior que $10 \%$ em relação à lâmina projetada, devido a bocais com diâmetros maiores que o necessário, para esse intervalo. Nos vãos $1^{\circ}, 2^{\circ}, 3^{\circ}, 5^{\circ}, 6^{\circ}, 11^{\circ}, 12^{\circ}, 13^{\circ}$ e no lance em balanço do PC 14 , nos vãos $1^{\circ}, 2^{\circ}, 3^{\circ}, 4^{\circ}, 5^{\circ}, 7^{\circ}, 8^{\circ}, 9^{\circ}, 10^{\circ}$, $12^{\circ}$ e o balanço do PC 15 e nos vãos $1^{\circ}, 2^{\circ}, 3^{\circ}, 4^{\circ}, 5^{\circ}, 7^{\circ}, 10^{\circ}$, $11^{\circ}$ e o balanço do PC 16 , a uniformidade foi "ruim" (< $80 \%$ ), com a maioria desses vãos apresentando lâmina coletada superior ou inferior a $10 \%$ em relação à lâmina projetada, também causada principalmente por bocais com diâmetros diferentes do necessário para esses intervalos. Do $1^{\circ}$ ao $4^{\circ}$ vão do PC 09, a lâmina coletada foi maior que a lâmina projetada, também causada por bocais de diâmetros maiores que os recomendados. Do $2^{\circ}$ ao $8^{\circ}$ vão do PC 11 , a lâmina aplicada foi muito elevada, aumentando a perda de carga, resultando em baixa pressão na extremidade final do equipamento, causado por bocais com diâmetros maiores do que os recomendados para esse intervalo, auxiliado por reguladores de pressão danificados, devendo ser substituídos. Houve vazamento nos "mangotes" da $2^{\text {a }}$ e $3^{\mathrm{a}}$ torre, contribuindo para redução dos índices de uniformidade, aumento da lâmina de irrigação e redução da pressão no final do pivô.

No PC 15 e PC 16 alguns reguladores de pressão e sprays estavam danificados, além de vários vazamentos nos pendurais e nos tubos do $1^{\circ}, 2^{\circ}, 3^{\circ}$ e $13^{\circ}$ vão, além de alguns emissores sem pendural do PC 15 . No PC 16 houve vazamentos nas curvas do pendural do $2^{\circ}, 9^{\circ}, 11^{\circ}$ e $12^{\circ}$ vãos, nas duas flanges dos tubos do $3^{\circ}$ vão e vazamento 
no "mangote" de transição e na flange de um dos tubos do $5^{\circ}$ vão. No PC-02, a lâmina coletada foi muito acima da lâmina projetada no $1^{\circ}$ vão, mesmo estando em bom estado de conservação, por possuir bocais com diâmetro maior do que o recomendado para esse intervalo do pivô, que tinha cerca de 4,5 anos de uso.

No $1^{\circ}$ vão do PC 03 , a lâmina coletada foi inferior à lâmina projetada, causada por bocais obstruídos. O pivô estava em bom estado de conservação, porém, existiam vazamentos nas "botas" de borracha que fazem a transição de uma torre para outra e um dos tubos da lateral, estando enferrujado que poderá resultar no tombamento do equipamento. Nesse pivô e no PC 08, o manômetro instalado no centro do equipamento, fundamental para o acompanhamento do funcionamento do sistema apresentou defeito. No PC 05, a lâmina coletada variou de forma acentuada em relação à projetada em, praticamente, toda a lateral, devido a bocais com diâmetros diferentes dos recomendados para esse equipamento, o mesmo ocorrendo no $2^{\circ}$ e $5^{\circ}$ vão do PC 10 . No PC 06, nos intervalos de 0 a $30 \mathrm{~m}, 63$ a $66 \mathrm{~m}, 115$ a $118 \mathrm{~m}$ e 177 a $180 \mathrm{~m}$ e no intervalo de 0 a $365 \mathrm{~m}$ do PC 07, a lâmina coletada foi inferior à projetada, causada por bocais com diâmetro inferior ao recomendado para esses intervalos. $\mathrm{O}$ mesmo ocorreu nos $1^{\circ}, 2^{\circ}, 3^{\circ}$ e $5^{\circ}$ vãos e no lance em balanço do PC 13 (10 anos de uso), além de vazamento nas flanges do $2^{\circ}$ e do $6^{\circ}$ vão. Constatou-se também ausência de pendurais no PC 07, PC 09, PC 12, PC 13 e PC 16, elevando a perda de água por evaporação e deriva. No PC 08, observa-se, no perfil de lâminas de água, 3 intervalos distintos: o primeiro do centro do pivô até $232 \mathrm{~m}$, com lâmina coletada inferior à projetada em cerca de $20 \%$, o segundo de $232 \mathrm{~m}$ até $365 \mathrm{~m}$, com $11 \%$ e o terceiro de $365 \mathrm{~m}$ ao final do pivô, com lâmina coletada próxima à projetada $(4,5 \%)$.

\section{CONCLUSÕES}

Dos 16 pivôs avaliados, 4 (25\%) apresentaram CUH inadequado $(<80 \%)$ e em 3 deles $(18,75 \%)$ o CUD foi inadequado $(<70 \%)$. A lâmina média coletada foi superior à projetada em 3 pivôs e inferior em 13, sendo a diferença maior que $10 \%$, em apenas um deles.

A maioria dos pivôs avaliados necessita de manutenção e reparos urgentes, especialmente para solucionar problemas como: bocais com vazão diferente da considerada adequada em algum intervalo do pivô, emissores total ou parcialmente obstruídos ou danificados, ausência de pendurais, reguladores de pressão danificados, resultando em pressões diferentes das especificadas em projeto, vazamentos como nas flanges, e velocidade de deslocamento do pivô diferente da indicada no relé porcentual.

\section{REFERÊNCIAS BIBLIOGRÁFICAS}

ASSOCIAÇÃO BRASILEIRA DE NORMAS TÉCNICAS. NBR 14244: equipamentos de irrigação mecanizada: pivô central e lateral móvel providos de emissores fixos ou rotativos: determinação da uniformidade de distribuição de água. Rio de Janeiro, RJ, 1998. 11 p.

BERNARDO, S.; SOARES, A. A.; MANTOVANI, E. C. Manual de irrigação. 8. ed. Viçosa: UFV, 2006. 611 p.

BONOMO, R.; MANTOVANI, E. C.; SOARES, A. A. Eficiência de irrigação em sistemas pressurizados, empregados na cafeicultura, em áreas de cerrado de Minas Gerais. Viçosa: UFV, 2003. (Boletim técnico, 8).

CHRISTIANSEN, E. J. Irrigation by sprinkling. Berkeley: University of California, 1942. 142 p. (Bullettin, 670).

CHRISTOFIDIS, D. Recursos hídricos dos cerrados e seu potencial na irrigação. ITEM - Irrigação \& Tecnologia Moderna. Brasília, n. 69/70, p. 89-97, 2006.

FRIZZONE, J. A. Irrigação por aspersão: uniformidade e eficiência. Piracicaba: ESALQ, 1992. 53 p. (Série didática).

HEERMANN, D. F.; HEIN, P. R. Performance caracteristics of self propeled center pivot sprinkler irrigation system. Transaction of the ASAE, Saint Joseph, v. 11, n. 1, p. 11-15, 1968.

HEINEMANN, A. B.; FRIZZONE, J. A. Custo da melhora da uniformidade de distribuição de água por um pivô central vs. economia de energia. In: CONGRESSO BRASILEIRO DE ENGENHARIA AGRÍCOLA, 24., 1995, Viçosa, MG. Anais... Viçosa: SBEA, 1995. p. 189.

HEINEMANN, A. B.; FRIZZONE, J. A.; PINTO, J. M.; FEITOSA FILHO, J. C. Influência da altura do emissor na uniformidade de distribuição da água de um sistema pivô central. Pesquisa Agropecuária Brasileira, Brasília, v. 33, n. 9, p. 1487-1491, 1998.

OLIVEIRA, L. F. C.; ALVES FILHO, A. S.; SILVEIRA, P. M. Distribuição de água no solo aplicada por um pivô central. Bioscia Jornal, Uberlândia, v. 19, n. 2, p. 79-87, maio/ago. 2003. 
PINTO, J. M.; SILVA, C. L.; OLIVEIRA, C. A. S. Influência de variáveis climáticas e hidráulicas no desempenho da irrigação de um pivô central no oeste baiano. Engenharia Agrícola, Jaboticabal, v. 26, n. 1, p. 76-85, jan./abr. 2006.

REZENDE, R.; GONÇALVES, A. C. A.; FREITAS, P. S. L.; FRIZZONE, J. A.; TORMENA, C. A.; BERTONHA, A. Influência da aplicação de água na uniformidade da umidade no perfil do solo. Acta Scientiarum, Maringá, v. 24, n. 5, p. 1553-1559, 2002.

RODRIGUES, T. R. I.; BATISTA, H. S.; CARVALHO, J. M.; GONÇALVES, A. O.; MATSURA, E. E. Uniformidade de distribuição de água em pivô central, com a utilização da técnica TDR na superfície e no interior do solo. Revista Brasileira de Engenharia Agrícola e Ambiental, Campina Grande, v. 5, n. 2, p. 187-191, 2001.

SANO, E. E.; LIMA, J. E. F. W.; SILVA, E. M.; OLIVEIRA, E. C. Estimativa da variação na demanda de água para irrigação por pivô-central no Distrito Federal entre 1992 e 2002. Engenharia Agrícola, Jaboticabal, v. 25, n. 2, p. 508515, maio/ago. 2005.

GOIÁS. Secretaria do Planejamento e Desenvolvimento. Plano diretor de irrigação em Goiás: termo I: proposições básicas. Goiânia, 2004. 106 p.

TEIXEIRA, M. B.; SOUZA, G. F.; MANTOVANI, E. C.; REIS, C. G. Estudo da influência da declividade do terreno e da utilização de reguladores de pressão na uniformidade de aplicação de água em pivô central equipado com LEPA. Viçosa: UFV, 2003. (Boletim Técnico, 8).

ZOCOLER, J. L.; CÉSAR, L. E. V.; VANZELA, L. S. Efeito da posição relativa da linha lateral de um equipamento de irrigação por pivô central na uniformidade de distribuição de água e eficiência da irrigação. Engenharia na Agricultura, Viçosa, v. 12, n. 4, p. 290297, out./dez. 2004. 